\title{
THE INFLUENCE OF CARBIDE DISTRIBUTION ON TEXTURE FORMATION IN A FAST ANNEALED Al-RILLED STELL
}

\author{
C.S. DA COSTA VIANA, L.P.M. BRANDÃO and \\ I.0. DE MEDEIROS \\ IME-SE/4 - BRASIL
}

\section{INTRODUCTION}

It is well known that the forming behaviour of sheet metals is directly related to their crystallographic textures. In Steels, a near ideal texture for a good performance in deep drawing operations can be described by the strong fiber components $\{111\}<\mathrm{uvw}\rangle$ and $\{$ hkl\} $<110>$ which maximize the R-values. Traditionally, the best behaviour in carbon steels is obtained for box-annealed $70 \%$ cold rolled materiall, 2. Besides being discontinuous, box-annealing is a very time-consuming treatment, this fact having contributed to the development of the continuous annealing process. However, the high heating and cooling rates of the latter does not allow an adequate texture control via aluminium nitride precipitation, as in box-annealing, giving rise to weak textured materials. Also, microstructural features were found to affect texture development in this process making it difficult to obtain high $R$-values in the final material ${ }^{3}$, ${ }^{4}$. In this respect, some workers have concluded that the presence of carbon in solid solution or as fine precipitades hinder the development of the $\{111\}$ <uvw> fiber components both in the cold rolling and the recrystallization textures 3-6. It is accepted that fine carbides are more detrimental than coarse ones ${ }^{5}$. Hutchinson ${ }^{3,4}$ suggested that better texture can be obtained in steels with fewer and coarser cementite particles. Recently, Magnabosco ${ }^{7}$ obtained strong $\{111\}<$ uvn> components in a solution treated steel sheet.

Annealing textures are influenced by many processing variables: coiling and annealing temperatures, heating and cooling rates, cold rolling reduction, among others. It is also dependant on the cold rolling texture. In particular, this is affected by the presence of hard particles in the matrix, as demonstrated by Dillamore et $a 1 .^{6}$, leading to a 
degradation of forming properties, as verified by Hosford and Zeisloft ${ }^{8}$.

In the present work an attempt is made to correlate the presence of carbon both in solid solution and as precipitates with the cold rolling and annealing textures of a low carbon Al-killed steel.

\section{EXPERTMENTAL PROCEDURE}

Commercial Al-killed steel for deep drawing operations coiled at $903 \mathrm{~K}\left(630^{\circ} \mathrm{C}\right)$ was used. Its chemical composition is shown in table $\mathrm{I}$. The material was received as hot rolled band with a thickness of $2.7 \mathrm{~mm}$.

Most of the hot rolled material was soaked at $973 \mathrm{~K}$ $\left(700^{\circ} \mathrm{C}\right)$ for 30 minutes, in a salt bath, and quenched to room temperature $\left(25^{\circ} \mathrm{C}\right)$ in brine. This ensured little alteration of the grain structure while dissolving about $50 \%$ of the cementite and precipitating most of the AlN.

Part of the quenched material was aged at different temperatures and time periods: $473 \mathrm{~K}\left(200^{\circ} \mathrm{C}\right)$ for 20 minutes, $673 \mathrm{~K}\left(400^{\circ} \mathrm{C}\right)$ for 10 minutes and $873 \mathrm{~K}\left(600^{\circ} \mathrm{C}\right)$ for 7 minutes. The time periods corresponded to the hardness peaks determined in previous ageing treatments. The idea was to obtain the largest influence possible of the precipitated particles on plastic flow and thus alter the crystal rotations and the rolling texture as a consequence.

Al1 specimens were $80 \%$ cold rolled in light passes and with liquid cooling, to avoid altering the initial treatments, and annealed at $1123 \mathrm{~K}\left(850^{\circ} \mathrm{C}\right)$ for 5 minutes, in a salt bath, immediately after. Specimen identification used the notation: $A R$ - as received, S - solution heat treated, SAX - aged at $\mathrm{X}(0,2,4$ or 6$)$ where $\mathrm{X}$ stands for the ageing temperatures $200^{\circ} \mathrm{C}, 400^{\circ} \mathrm{C}$ or $600^{\circ} \mathrm{C}$, respectively.

The texture was quantified by the crystallite orientation distribution function (CODF) using the method of incomplete pole figures developed by Morris. Three pole distributions were used and the series coefficients were calculated to the order of $l=20$. No zero-order correction was used. The CODF sections were drawn in times random units, the dotted line corresponding to 1 and the others to increments of 1 . 


\section{RESULTS}

The as-received material showed a ferritic microstructure with a grain size of $8.3 \mu \mathrm{m}$ and few colonies of pearlite. This microstructure did not undergo great change after solution heat treating. MOst of the pearlite colonies disappeared but significant grain growth was not observed.

Figure 1 shows the $\phi=45^{\circ}$ sections of the CODF for the cold rolled materials. The textures can be represented by - $\{111\}<\mathrm{uvw}\rangle+\{$ hkl $\}<110\rangle$ components with peaks near A $\{111\}<11 \overline{2}\rangle, \mathrm{B}-\{223\}<1 \overline{1} 0\rangle$ and $\mathrm{C}-\{001\}<110\rangle$. By far the highest peaks occur fot the solution treated material. One can see that component $B$ in material $S$ practically disappears in SA2 and SA4 but returns slight1y in material SA6. The highest peak shifts from the B component, in material $\mathrm{S}$, to the $\mathrm{C}$ component in the others. Figure 2 is a plot of function height versus initial condition for the rolled materials. Here, the cold rolling texture of the AR material was included for comparison, Clearly the $\{111\}<u v w>$ components pass through a maximum for the $S$ material and through a minimum for the SA2, increasing again for the SA6 condition, the $\mathrm{C}$ component remains nearly constant.

The CODF for the annealed materials can be seen in figure 3. Again the textures can be represent by the two partial fibers mentioned above but, now, the peaks occur near components A, C, D $-\{111\}<1 \overline{1} 0\rangle$ and $\mathrm{E}-\{113\}<1 \overline{1} 0\rangle$. The highest peaks, associated with the A component, occur again in the $\mathrm{S}$ material, where the $\mathrm{C}$ component has the smallest value. Figure 4 shows the function height versus initial condition for the annealed materials. Again, the maximum occurs near $\{111\}\langle u v w>$ for the solution treated material and the minimum for materials aged at $473 \mathrm{~K}\left(200^{\circ} \mathrm{C}\right)$.

\section{DISCUSSION}

From the results it is clear that the presence of carbide particles in the matrix affects the cold rolling texture devolopment in sheet steels. In figure 2 its is also clear that the $\{001\}<u v w>$ components are much less sensitive than $\{111\}<$ uvw > components. In fact the latter increase considerably in the absence of carbides, as in material $\mathrm{S}$, and is deeply reduced in the aged materials, while the $\{001\}$ <uvw > components remain practically constant. At $473 \mathrm{~K}\left(200^{\circ} \mathrm{C}\right)$, orthorhombic cementite precipitates as platelets on $\{110\}_{\alpha}$ planes in $\left.<111\right\rangle_{\alpha}$ directions ${ }^{9}$. At this 
temperature, at peak hardness, it must be a fine and we11 distributed precipitation, capable of stronghy interfering with the dislocation motion on the pencil glide $\{h k \ell\}<111>$ slip systems. For some reason the additional displacements resulting from the dislocation-particle interference seem to affect the rotation path of the crystals towards $\sim\{111\}$ <uvw> end orientations more effectively than towards $\{100\}$ $\langle 110\rangle$, leading to a greater randomization of the rolling texture. This in turn leads to more randomized annealing textures. As the particles coarsen their influence decreases and the material returns to a situation similar to the AR condition, as can be seen for materials SA4 and SA6 in figure 2 .

The analysis of the recrystallization textures is more complicated since both nucleation and grain growth are involved. As pointed out somewhere $e 1 \mathrm{se}^{10}$ the particles tend to redistribute the stored energy of cold work throughout the crystal orientations leading to a more distribution of orientations of the recrystallization nuclei. Their growth is again affected by the particles, the more so the finer their distribution, contributing to additional competition and texture randomization. This general effect can be seen in figures 3 and 4 . There it can also be seen that the strongest annealing texture occurred in the solution treated material contrary to other author' $s^{3}$ reports about the detrimental effect of dissolved carbon in rapidly annealed steel sheets.

The extreme microstructural conditions used in the present work point to a general influence of particles on both rolling and recrystallization textures, underlining what some researchers had already indicated: ${ }^{3,4}$ a clean ferrite matrix with a few spread out coarse particles yields high $\mathrm{R}$-values in continuous annealing.

\section{CONCLUSIONS}

1 - The general influence of a fine carbide distribution in fast annealed sheet steel is to decrease the $\sim\{111\}<$ uvw $>$ components of both the cold rolling and the annealing textures.

2 - The solution treated material yields the highest peaks in the $\sim\{111\}<$ uvw $>$ components for both the rolling and the annealing textures. 


\section{ACKNOWLEDGEMENTS}

The authors thak CNPq and IME for material and financial support.

\section{REFERENCES}

1 - R.L. Whileley and D.E. Wise, Flat Rolled Prod. III, Ed. A.E. Earhart, Chicago, 1962, p. 47.

2 - D.J. Goodwill, PhD thesis, Univ. of Cambridge, England, 1973.

3 - W.B. Hutchinson and K. Ushioda, Proceedings of 7 th ICOTOM, Noordwijkerhout, The Netherlands, (1984), 400.

4 - W.B. Hutchinson and K. Ushioda, Scand. J. Met., 13(1984), 269 .

5 - S. Ono, P. Delaneau and B. Thomas, Porceedings of 7 th ICOTOM, Noordwijkerhout, The Netherlands, (1984), 359.

6 - I.L. Dillamore, W.B. Hutchinson and D.L. Morris, Proc. Effect of Second-Phase Particles on Mechanical Properties of Steels, The Iron and Steels Institute, London, (1971), 190 .

7 - A.S. Magnabosco, M.Sci Thesis IME, Rio de Janeiro, 1986,

8 - W.F. Hosford and R.H. Zeisloft, Met. Trans., 3(1972), 113.

9 - Steels, Microstructure and Properties, R.W.K. Heneycombe, Edward Arnold, 1981. 

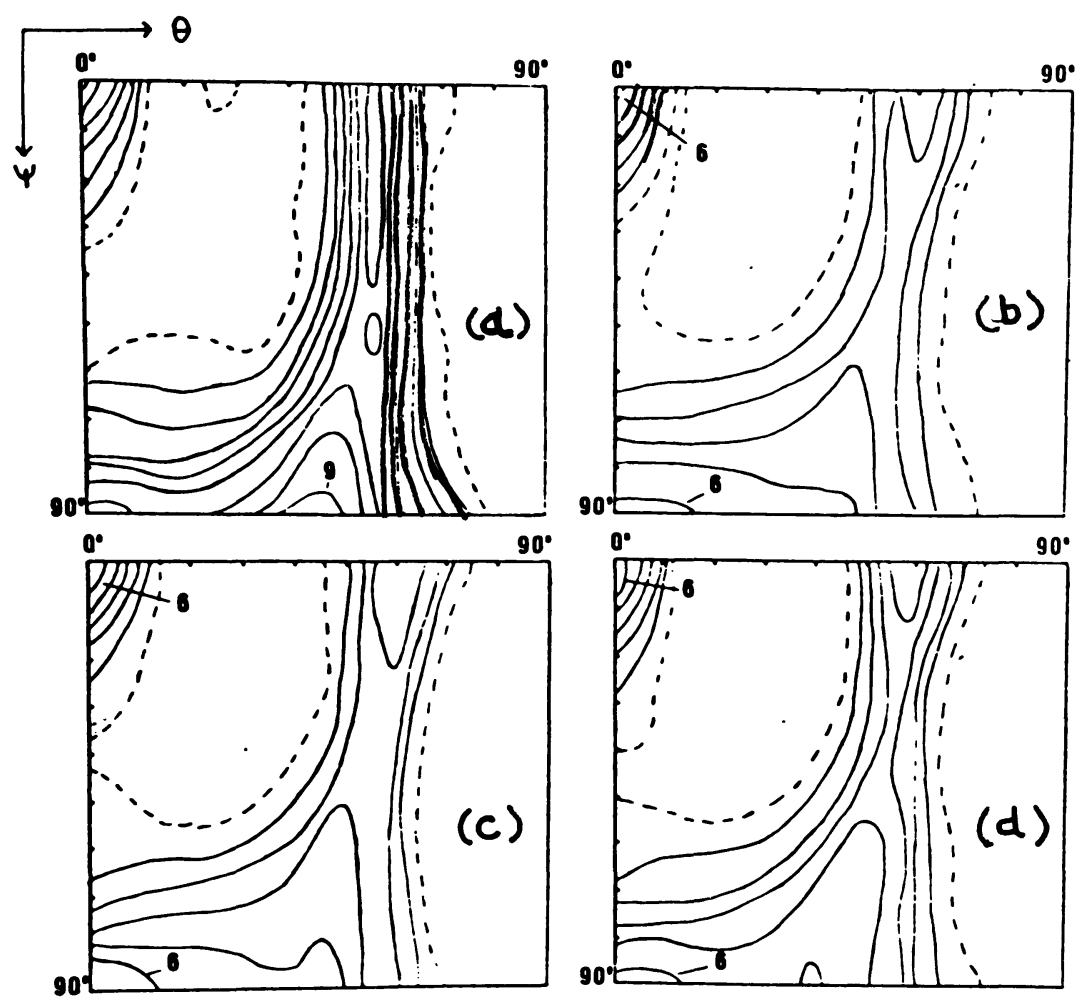

Figure $1 \quad \phi=459$ sections of (a) S (b) SA2 (c)

SA4 and (d) SA6 materials

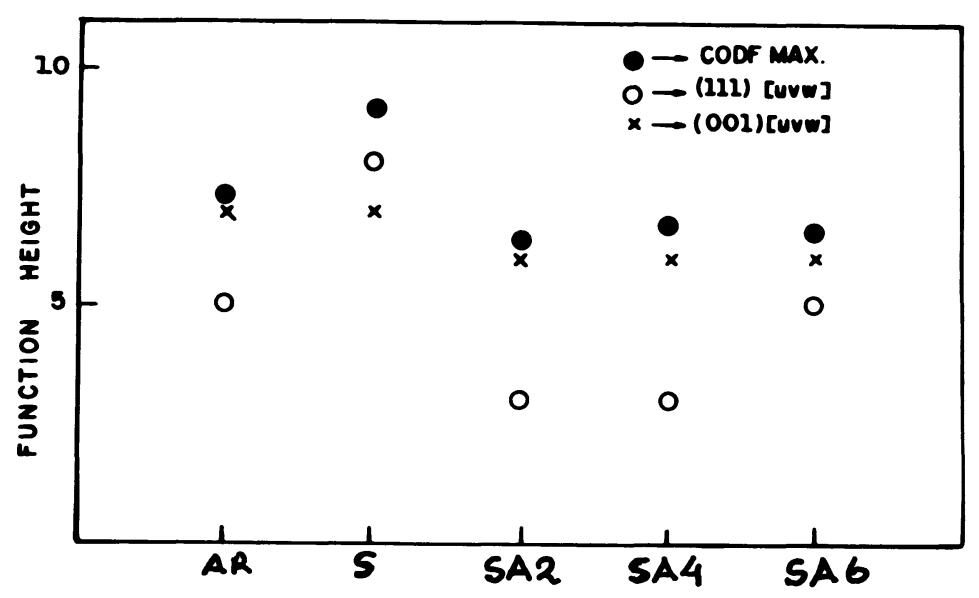

Figure 2 Function height versus previous conditio for cold rolled materials 

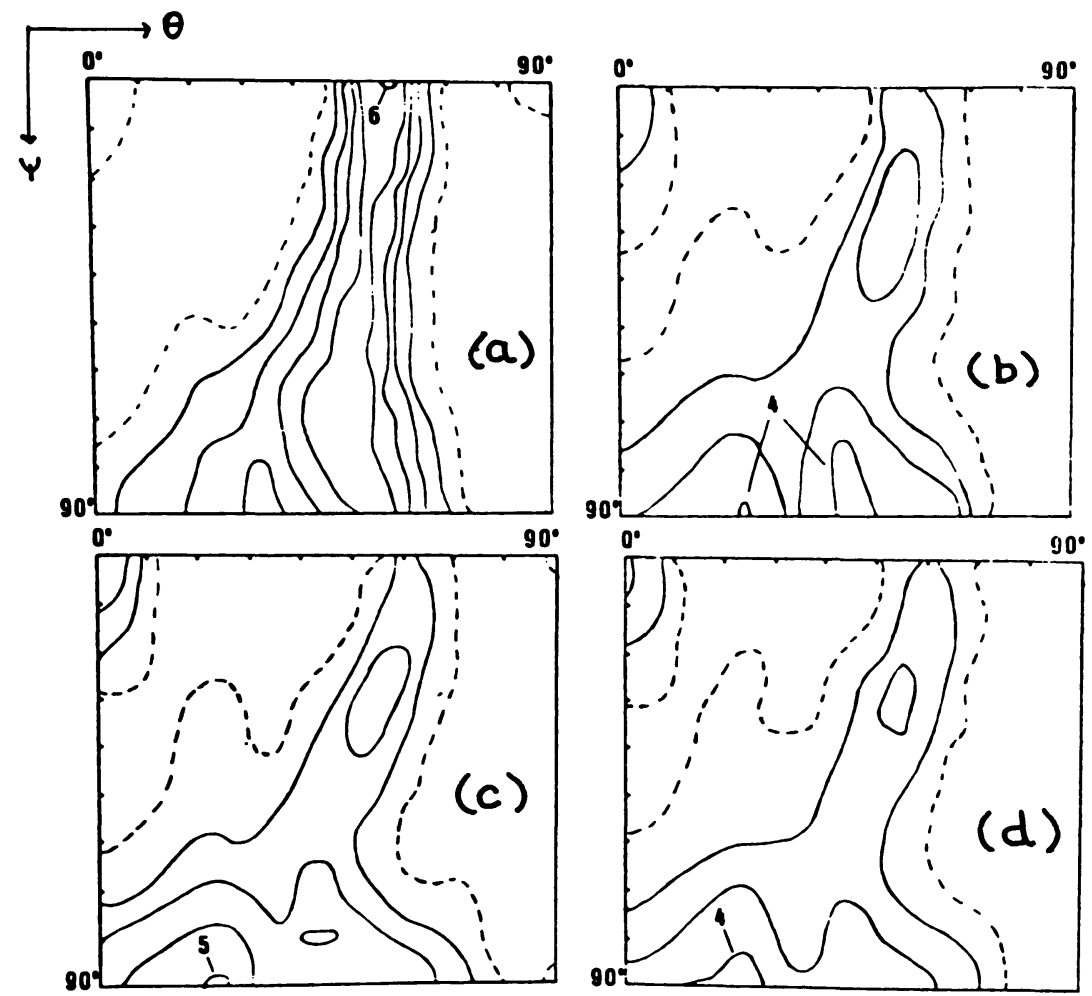

Figure $3 \phi=450$ sections of (a) $s$ (b) SA2 (c) SA4 and (d) SAG annealing textures

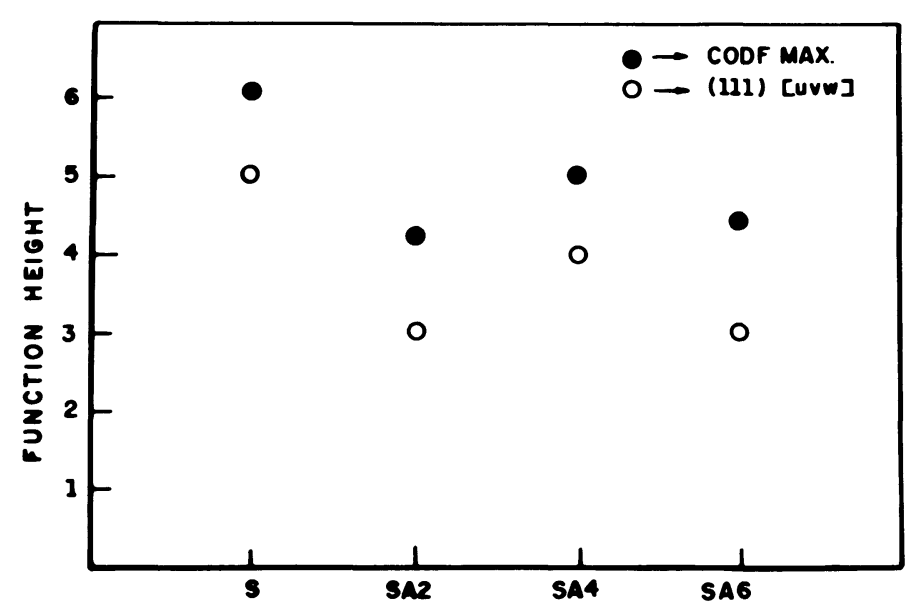

Figure 4 Function height versus previous condition for annealed materials 